\title{
The lemon taste of limos
}

\author{
F. M. Riegler
}

Published online: 12 June 2014

(C) Springer-Verlag Wien 2014

\section{Dear reader,}

Allow a special taste, mind to sense the globe now, time is ready for a special summer time blues sun shine serenade. Out balanced full globe traveler, cars, girls, woman, enjoyment, hard work business, development of novel ideas within the frame of personal freedom made him rise and prosper. Sugar sweet activities interposed into the working channel to highly, successfully foster the economic background, filled his life until the stroke hit his wings and somehow broke his enthusiasm partially. But he fought and rose up again to some extent, made it to journey over parts of the globe, across seas and mountains, lakes and high lands. Finally the poison of sugar came to shake his body to soul and a no more recovering post-diabetic body turns back to soil giving rise to novel seeds to open new eyes of shine and fortune. Thus he schedules regular returns. Recently I asked him: "How are you?" and he sent a sign of infinity. Again I asked him: "How are things going?" and he responded: "My life is a rainbow, I am flying to the sky, my life is a rainbow, I am flying so high, my life is a rainbow, I am kissing the moon, my life is a rainbow, I gonna see you soon; oh see the people, as they are moving in the street, oh see the people, as they been dancing on their feet, oh my life is a rainbow, so I would not have to go".

After a short period of timeless pause he continued to mind: "And this is how I would suggest to explain why your world, that has been mine before, at present and since ever strikes back, the medical and non-medical world. This seems to be why you develop impairment

F. M. Riegler ( $\square)$

Reflux Medical,

Mariannengasse 10/9,

1090 Vienna, Austria

e-mail: martin.riegler@refluxmedical.com of life quality and conditions that you would define as disease, within the medical and non-medical world and industry." The essence of it all is lack, hunger (ancient Greek: $\lambda_{1} \mu o$ ó; LIMOS) (Fig. 1). Going in line with the perceptions throughout my life this lack affects major representations of our life.

First of all, there is the lack of adequate respect for each other during communication, there is this lack of acceptance of others' opinions, there is this lack of giving value to the counterparts and there is the lack of understanding that all we perceive, either materialistic or mentally, is borrowed for a so-called life time. There is a lack of an open minded approach. In addition, there is a lack of understanding that there is no difference, that there are no actor and anti-actor; the truth is that all is one, and that this one represents a continuum of energy, and that it seems to consist of different parts because of the limitations of our systems of perception, interactions of light and matter, and these systems of perceptions cut out of the continuum what we want to see, we wish to see, according to our will, ipsissime cum manibus individualibus. The basis of all perceptions contains the pseudos. This is why I have to come with the notion that all our knowledge represents translation of state of mood, swing of emotion into the language of reproducible signs, words, colors, and melodies. Design of matter and space. And here you go and there you go, Hamlet, Jahgo, mind come: there exists a lack of education, for the youth and the elderly, in general, in medicine and regarding the how to behave issue.

There is a major and profound lack of attention, love, coziness, expression of gratitude in the form of a so-called positive reaction to what you have done: hey reader, you will not get positive response, it is all taken for granted, you are exploited and it is taken for granted, how can that have a duration? As a matter of fact, so far you did a good job, you did not mind reading and did not give up reading those lines, and it may be due to the fact that some 


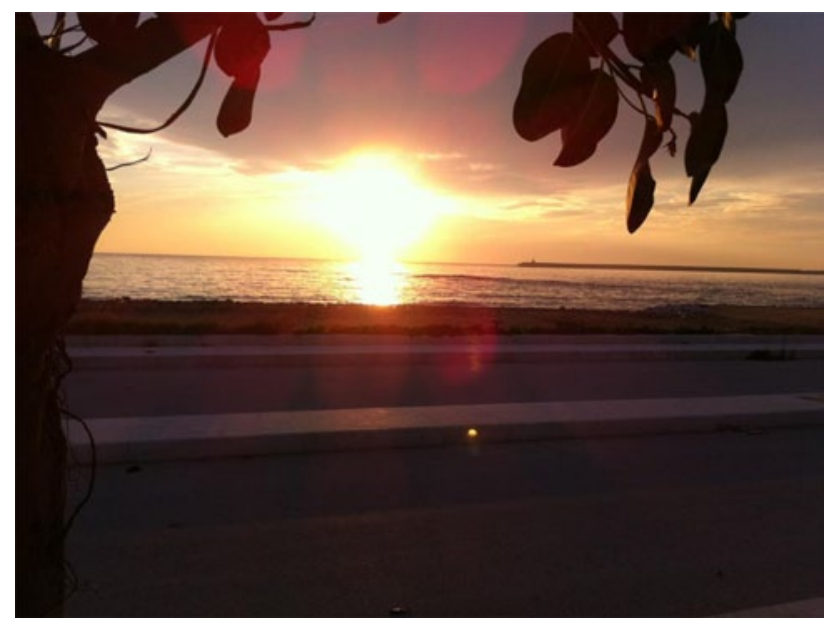

Fig. 1 Sunset induces limos, lack of light, hunger after a new day. The image mirrors the idea of the author, that there is no being without limos, that being is limos, searching after more. (Source: Image obtained in Sicily, Europe, Jan 2014, using iPhone technology)

of the LIMOS affects you too? They have taken it out of you, prevented you to get it. List the lack, taste the lemon of limos, heartburn, throat, and tongue burn. Maybe YOU, dear reader, SUFFER the LIMOS, some specific type of LIMOS, too? Did you get attention, respect and a socalled "thank you, guy", for what you have done? Instead you are prone to lack the taste of limos, acidic to sweet, sweet to acidic, too. Did you perceive an icon of emotion which puts you back into the middle of your road? Traffic came to blow out your brain. As a matter of fact, you are hungry for attention and respect.

All those guys around you, male, female, inter-sex rail road runner and over sex, all those so-called push-ups and jumpers are full of idolatry, idols full of icons filling the space of lack. They all wish to be in the center and shine within the furious and highly dangerous light of self-esteem! This is why we all lack a world free of greed, envy, hate, and egoism. It all has to act forward, there seems to be a lack of control, it seems the world gets out of control, has gone out of control, since ever of its existence, may be? And there is lack of real attention you have gained from your parents, as a consequence the same you offer to your kids, children are sexually misused on a daily basis, perversion is the lack of love, attention, and understanding, closing the ring of sadness. And there is a lack of passion! Misbehavior results from this type of limos. And later in these lives the lack manifests in the form of so-called psychosomatic disorders.

Of note the esophagus seems to play an increasingly essential role for staging the limos. The tube arises from the neck and throat, adjacent to the brain and takes down two distinct nerve gullet strings, which directly flare out of cerebral nerve nodes. Conceptually emotions are energetic field responses running around the brain and thus may stimulate the activity of propagations into the body. This is why some may develop stress induced perception in the throat, neck, shoulder, thorax, heart, stomach, gut, spine, and legs etc. based on the genetic profile, formatting. Others develop secretion from tears to cry along the gut, i.e., diarrhea, essentially and basically it is all the same. There is this lack of understanding that duration requires time, things, and actions require THEIR time.

Believe me, here in my current state of mind, existence, and perception I do not wear a watch, but I have time, lots of time. There is no past, present, and future time, there is mind and it comes, goes and floods, according to its needs, giving and taking what it has to give. Time is the wing, and has to move if you want to fly up and gain the idea of an overview. But this time, dear reader, is never depicted and visualized within the context of a clock, even the best of all, the Swiss time, lacks these attributes. There is a lack of understanding that we work, live, act, and react in the form of models. Out of the all we excise a part, the part is then defined to work, serve and function as the measure and the whole is compared with regard to the part, the so called instrument, and this is reproduced and cataloged and here we start to talk about evidence based academic science.

There is no smoke without fire, but you will never be aware of the essence of fire, smoke, and rain, if you stop in front of the border to the un-measurable, where there starts the world of emotion, universal swing of mood, tune of the $I$ and $I$. Would there be you, dear reader, be those lines, the interaction between you and the words, time space and all the other models without the I and I? the Tat Vam Asi, the logos, the cosmos, the ma.at, the physis, the zoon and the life-long brain, throat-torah, gullet-esophagus to anus MAGIC trial, which ended in the creation of gods and THE god.

Now it is not us, who has to take the responsibility for our actions, not the kone (=the me), and the force that takes our responsibility instead of us has been put into heavenly dimensions and thus serves as the idol focus for adoration and keeps us free from being responsible. In addition to the lack of taking responsibility there is the limos lack of discipline.

Life style beverage mixes spread out the sugar, alcohol, and other drugs into the melody of our weak personalities. Concentrated sugar induced floury floods of wingless waves disintegrate the continuity of our metabolism and represent in the form of diseases been taken care of in the out-field flyers of internal medicine and many more LOGOS: neurology, cardiology, radiology and many more. Lack of discipline and over doses of concentrated sugars bring the body to the surgeon, who starts to intersect, dissect and transect. As a result the INSECTUM flies home via the final logos road track: pathology. Most times, I myself had great luck, I have NEVER been turned to an INSECTUM and made it to here without even touching the pathology home lands. Thus, I have to thank my friends and beloved, who allowed me to vanish after having a great cup of coffee, without sugar. Life is a shine into matter, time beams perception, do not forget to give room and space to love, otherwise it will all hit you at the end. 
Dear reader, if you like to use excel to calculate the results of your studies, trials and examinations, if you love statistics and $p$-values, there is something that has been expressed within the ancient, old Egyptian notion of ma.at, which you should not miss: at the end before you become a star, allowed to borrow the life of a rainbow, all the plus and the minus is brought down to zero, as a zero we start and as a zero we end as the energetic state of man. What remains is limos, the cause of all our perceptions, emotions, body and soul shake down parties. Limos is the reason for all. Being is limos, lack of unfold. Unfortunately, I was not able to translate this concept adequately to the second shorter part of my life, the part after the stroke, before and during my diabetic representation. Thus I lacked adequate life quality during the last part of my existence in your world. But I have been hungry after sugar and sweeties. School medicine did me a favor, made me stand and walk somehow through the power of the pills, drugs and numerous injections into the eyes. Now I have made it to become a beam of light, now I feel easy and full of good vibrations within the mind and thought of my friends, and thus I am able to provide good energies for them. The author of those lines has been one of my best and closest friends and I am happy and glad that I have been a second father to him. His parents and his sister, all outstanding personalities, entirely unique, have educated him with the wonderful richness and purity of mental uprising in the form of Western philosophy, art and grafts, from Bach to Beethoven, Handel, Wagner, Brahms and Mahler, from Heraclitus and Parmenides to Heidegger, from James Joyce, Marcel Proust, Robert Musil to his beloved Thomas Bernhard. I had the luck that I was allowed to show him the road to the other half of it. Cars, women and: I opened his eyes to the Third World. There, emotion continues to respond in the form of tales, myths and mysteries. As a consequence, reggae took him out of the gardens of babylon, out of the reach of greed, envy and hate. And finally, as he always used to say, it made him become a freedom fighter, a roots rock rubber dub body and soul rebel against the bad emotions around him, against the LIMOS!!! This is what it seems to take as the counterpart to what is going on today, creating the hunger. And we do not have to forget, any expression arises out of the state of hunger, limos! Hunger induces action in the form of speech, art and grafts (Fig. 2).

Since no man is an island, this track and many more helped him find his way out of the bad vibration systems of his medical school. He felt that the medical school system was not entirely bad at all. But there has been mixed too much of the bad into the good. He thought that this was not entirely due to the weak personalities of leaders doing their brave system protecting and fostering job at his medical school. Most of it was the result of an unfortunate antagonistic orchestration between the system, the leaders, their responsibilities, the employees, the separation of docs, and nurses through the hard cutting knives of the system. The positions involved are: supra nova mega nurse spider (come into my network and let me be your spider), hospital director (I am the clown of

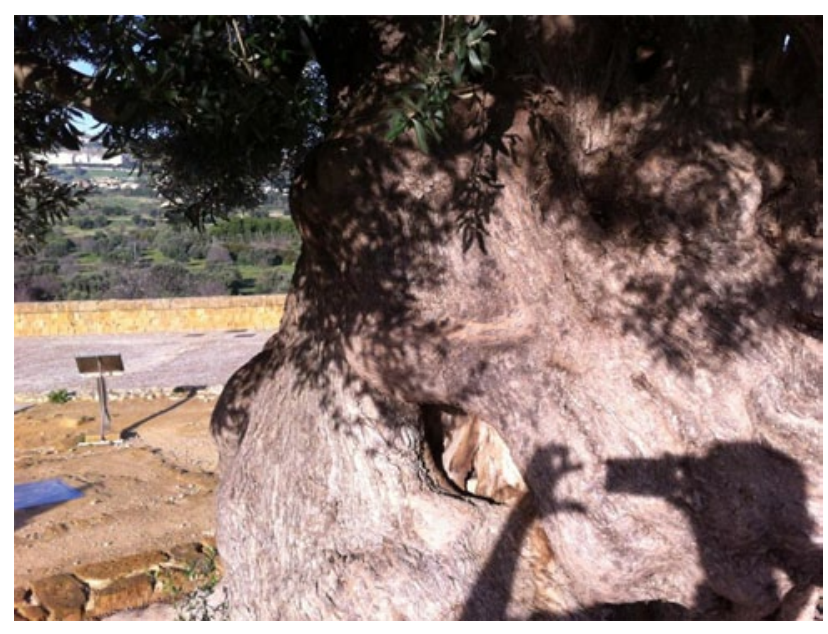

Fig. 2 Shadows are lack of knowledge about the creators of the shadow. Thus the image mirrors the idea of the author, that limos, lack is the cause of any reasoning, hunger creates action, words, arts and grafts, as depicted in the text. (Source: Image obtained in Sicily, Europe, Jan 2014, using iPhone technology)

my own fortune), the princeps academicus (in Europe the country has always been taken from east to west, mostly along the infrastructure of a river) and the nonpolite political power games between the different structures, positions, and action-takers in the form of a fun factor storyteller funeral by Sophokles: all your speeches are well constructed networks of vocal glitter, whom to trust, but not you? Over time increased the lack-limosof interest, identification with the institution. People are hungry to be accepted not only as functioning part in a modern women and man consuming machine. Frustration took over for most parts of the members at all sides. Thus at some point he felt: either they kill me or I have to step out, at least transiently. Stepping out was the message of the semi hot summer night dream while being on call in August 2013.

I have shown him the bliss upon bliss of running and seeing things openly easy. Academos fought a war, ended in victory and consequently he was given the garden adjacent to the outer surface of the town wall of Athens. Academy rose out of a war, and thus it prospered as a victory. Dedication counts. Thus, today my friend stands there in balance and wings around with me in a daily and continuous communication. I am happy to see him in good shape. The question remains: who exploits you next? You are, but you are closer to the essence if friends, parents and partners lead you there. Maybe you feel that you wish to follow the leader in you, try to individually structure your life and foster freedom of reasoning". Thus vanished his mind to be a pause, a limos.

The increasing perceptions of limos of lack and hunger of acceptance and respect. Consequently, looking out for a new well-being fostered the representation of an adequate taste of the time to mirror the needs, hopes, and desires of the central European population. A new tolerance inducing figure has been taken out of the 
ashes of underestimated emotions and designed, created, and born in the form of a musical wave arising out of the legacy of our ancestors. And most importantly our good friend producer David is on the road again. Twisted minds are hard workers. Successful times are ready for emotional rescue. If well taken, this translates into better understanding of disease, diagnosis, and treatment. Oncology masks and hides. We should not break the mirror, we should watch out and keep on going to respect each other and the lemon taste of limos. It could affect us, too! However, we have to bear in mind: tolerance is expensive; the European continent has to ask if it can afford tolerance. It is not enough to preach and favor tolerance, one has to provide the economic basis for tolerance. Starving provokes intolerance! Keeping this in mind we should offer and orchestrate the basis for a fascinating future in Europe.
Go out to prosper to be better and have fun at do. Foster the rise of a positive, happy new day. Let us afford tolerance. Stay tuned and enjoy summer.

\section{Acknowledgement}

The author thanks his family, friends, and patients, who contributed to strengthen his mind in favor of a critical reasoning and a positive, highly respectful approach towards life. In addition the author thanks the publisher, editors, reviewers, and authors of European Surgery. Without their attention, help and support, this important academic European project would not be able to harmonize and outbalance the "live, take \& give".

\section{Conflict of interest}

The author indicates that there exists no conflict of interest. 